\title{
Fusarium fujikuroi species complex in Brazilian rice: unveiling increased phylogenetic diversity and toxigenic potential
}

\author{
Camila P. Nicolli ${ }^{*}$, Miriam Haidukowskic, Antonia Susca ${ }^{c}$, Larissa B. Gomes ${ }^{a}$, Antonio \\ Logrieco $^{c}$, Gaetano Steac ${ }^{c}$ Emerson M. Del Ponte ${ }^{b}$, Antonio Morettic, Ludwig H. Pfenning ${ }^{a}$
}

a Departamento de Fitopatologia, Universidade Federal de Lavras 37200-000, Lavras, MG, Brazil

b Departamento de Fitopatologia, Universidade Federal de Viçosa 36570-900, Viçosa, MG, Brazil

C Institute of Science of Food Production, 70126, Bari, Italy

* Correspondence: Camila P. Nicolli camilaprimierinicolli@gmail.com

Last modification: 31 Jan 2020
Fusarium fujikuroi species complex (FFSC) species are commonly encountered infecting rice, but knowledge of the diversity and toxigenic potential of the species is lacking in Brazil, the largest rice-producing country outside Asia. One hundred FFSC isolates obtained from national rice were identified using morphology and phylogeny of $T E F, C A L$ and $T U B$ genes. Eight previously known and one new phylogenetic species were identified. Three species accounted for around $60 \%$ of the strains: F. fujikuroi $(\mathrm{n}=23), F$. proliferatum $(\mathrm{n}=22)$ and $F$. verticillioides $(\mathrm{n}=16)$. The less frequent species were $F$. volatile $(\mathrm{n}=8), F$. anthophilum $(\mathrm{n}=6), F$. pseudocircinatum $(\mathrm{n}=4), F$. sterilihyphosum $(\mathrm{n}=2)$ and $F$. begoniae $(\mathrm{n}=1)$. The new Fusarium sp. was represented by 18 isolates. All species produced at least one of the analyzed mycotoxins [beauvericin (BEA), fumonisins (FBs), moniliformin (MON) and enniatins (ENNs)]. BEA was produced by all species but $F$. verticillioides. The FBs (mainly FB1) were produced mostly by $F$. fujikuroi, F. proliferatum and $F$. verticillioides. $F$. begoniae and $F$. verticillioides did not produce ENNs and $F$. sterilihyphosum and $F$. begoniae did no produce MON, while the other species produced MON and ENNs. Our results contribute new knowledge of the diversity, geographical distribution and hosts of FFSC species.

Keywords: Oryza sativa, Fusarium fujikuroi, fumonisin, beauvericin.

\section{Introduction}

Rice (Oryza sativa L.) is one of the major staple foods in the world and is produced mainly in Asian countries (AMIS, 2019). Brazil is the largest rice-producing country outside Asia (ERS, 2019). Among several diseases that affect rice, those caused by mycotoxigenic fungi are most important because of the risk for food safety due to mycotoxin contamination of the 
rice grain (Neme et al. 2017). Mycotoxigenic fungi are spread across several genera but those of the Fusarium genus that infect and colonize flowers and developing rice kernels in the field are most important, while other genera occurs in rice grain after harvest (Gonçalves et al. 2019). The high diversity of Fusarium species infecting rice increases the risk of mycotoxin contamination given the large variation in their toxin profile (Shi et al. 2017; Savi et al. 2018).

Species of the F. fujikuroi species complex (FFSC) is commonly found in rice grains, especially F. fujikuroi, F. proliferatum, and F. verticillioides (Wulff et al. 2010). FFSC species produce a wide range of mycotoxins including fumonisins (FBs) (Rheeder et al. 2002), moniliformin (MON) (Marasas et al. 1986), beauvericin (BEA) (Logrieco et al. 1998), fusaproliferin (FUP) (Moretti et al. 1996), enniatins (ENNs) (Nicholson et al. 2004) and fusaric acid (FA) (Bacon et al. 1996). Fusarium fujikuroi is the main cause of Bakanae disease of rice, a worrisome seed-borne disease occurring worldwide (Bashyal 2018). However, F. anthophilum, F. proliferatum and F. verticillioides are also found in association with bakanae (Zainudin et al. 2008; Carter et al. 2008; Wulff et al. 2010; Amatulli et al. 2010; Hossain et al. 2015; Bashyal 2018). Bakanae disease has been increasingly diagnosed throughout all rice-growing regions in the world and is considered an increasing problem in Asia due to changes in climatic patterns and some cropping practices (Zainudin et al. 2008; Hossain et al. 2015; Bashyal 2018). In Brazil, this disease was reported almost 50 years ago, as caused by F. moniliforme (syn. F. verticillioides), based on morphology identification (Amaral et al. 1970). Since then, no further reports were made and Bakanae is not listed as a disease of concern to Brazilian rice farmers. 
Other species complexes commonly found in rice include $F$. graminearum (FGSC; Gomes et al. 2015), F. incarnatum-equiseti (FIESC; Avila et al. 2019) and F. chlamydosporum (FCSC; Savard et al. 1990; Kanaan et al. 1993; Islam et al. 2012). The large diversity of mycotoxigenic Fusarium spp. in rice grains (Wulff et al. 2010 Hossain et al. 2015; Avila et al. 2019; Moreira et al. 2019), increases the risk of mycotoxins (Savi et al. 2018; Gonçalves et al. 2019). Besides the aforementioned mycotoxins produced by FFSC, deoxynivalenol (DON), fusarenon X, nivalenol (NIV) (Tanaka et al. 2007), zearalenone (ZEA) (Lee et al. 2011), T2 (Soleimany et al. 2012) have been reported in rice. In general, the individual levels of contamination by one mycotoxin in rice are relatively lower compared with Fusarium mycotoxin toxins affecting wheat or corn, such as deoxynivalenol (Plattner and Maragos 2003; Sobrova et al. 2010). However, since 2010, multiple occurrences of mycotoxins of various toxicity, due to the large diversity of Fusarium, has been reported in rice further increasing the risk to consumers (Bansal et al. 2011; Gonçalves et al. 2019).

A recent work of FFSC species identified 26 strains of $F$. verticillioides infecting Brazilian rice based on morphology, with four strains identified based on the phylogeny of the RPB2 locus (Savi et al. 2018). Given the higher resolution of molecular methods, we hypothesize that the diversity is higher than reported and a more clear picture of the species limits within FFSC can be inferred from phylogenetic analysis of larger sample of strains. We addressed this issue using a large collection of FFSC strains isolated from samples of panicles and grains collected at the main rice-growing regions of the country. Given that FFSC strains are capable of producing a wide range of mycotoxins, knowledge of their toxigenic potential is critical for risk assessment and decision-making regarding targets in mycotoxin surveys, especially in the region where regulatory agency has 
promulgated maximum tolerated limits of mycotoxins in rice (ANVISA 2017). Thus, the aims of this study were i) identify the FFSC species with a molecular approach; ii) study their genetic diversity and their phylogenetic relatedness and iii) analyze the mycotoxin profile of FFSC at species level.

\section{Materials and Methods}

\subsection{Sampling, strains collection and isolation procedures}

The 100 strains of FFSC used in this study were obtained from surveys conducted at the main rice-producing regions of Brazil during three different seasons. The strains were originated from three different collections defined based on the season and time of sampling (pre- or post-harvest): a) historical sample (2019 to 2012) of 10 FFSC-like strains isolated from mature grains produced in Rio Grande do Sul (RS) state; b) a contemporary (2014/15 and 2015/16 seasons) sample of 47 strains isolated from harvested grains obtained from fields at seven states: RS, Goiás (GO), Mato Grosso (MT), Tocantins (TO), Maranhão (MA), Roraima (RR) and São Paulo (SP) States; and c) a contemporary field sample (2015/16 season) of 42 strains isolated from panicles collected randomly, during harvest, in rice fields in the states of Santa Catarina (SC), RS and TO (Supplementary Table 1).

More than six hundred samples were analyzed. For each one, two hundred grains were plated on sterile saline solution soaked blotters (filter papers) in germination boxes (Gerbox) and incubated at room temperature $\left(25 \pm 3{ }^{\circ} \mathrm{C}\right.$ ) for 12 days (Leslie \& Summerell, 2006). Colonies with characteristics of the Fusarium fujikuroi species complex (FFSC) were 
isolated in pure culture. Examinations were made using stereo and compound binocular microscopes, and one strain per grain sample was isolated on MA2\%. Preliminary identification of the strains was based on morphological characters of the conidiophores, conidiogenous cells, and presence or absence of polyphialides and conidial chains (Leslie \& Summerell, 2006). The isolates were deposited in the Coleção Micológica de Lavras (CML), Departamento de Fitopatologia, Universidade Federal de Lavras, Brazil (http://www.dfp.ufla.br/cml). Duplicates were deposited at ITEM - Agro-Food Microbial Culture Collection of the Institute of Sciences and Food Production (ISPA), Puglia, Bari, Italy (http://server.ispa.cnr.it/ITEM/Collection/).

\subsection{DNA extraction, PCR assays and sequencing}

DNA was extracted and purified from fresh mycelium using the "Wizard® Magnetic DNA Purification System for Food" kit (Promega) according to the manufacturer's protocol. Phylogenetic relationships were investigated by amplifying and sequencing the housekeeping genes translation elongation factor 1- $\alpha(T E F)$, calmodulin $(C A L)$ and $\beta$ tubulin (TUB). Fragments of TEF gene were amplified using the primer pair EF1 and EF2 (O'Donnell et al. 1998). Cycling conditions were: initial heating at $95^{\circ} \mathrm{C}$ for $90 \mathrm{~s}$, following by 40 cycles $\left(45 \mathrm{~s}\right.$ at $95^{\circ} \mathrm{C}, 1 \mathrm{~min}$ at $52^{\circ} \mathrm{C}$ and $2 \mathrm{~min}$ at $72^{\circ} \mathrm{C}$ ), final extension at $72{ }^{\circ} \mathrm{C}$ for 5 min. Fragments of CAL gene were amplified using the primers CL1 and CL2 (O'Donnell et al. 2000) and the TUB gene were amplified using the primers Bt2a and Bt2b (Glass \& Donaldson 1995). Before sequencing, PCR products were purified with the enzymatic mixture EXO/FastAP (Exonuclease I, FastAP thermosensitive alkaline phosphatase, Thermo Scientific). Sequence reactions were performed using a BigDye Terminator v3.1 Cycle 
Sequencing Ready Reaction Kit for both strands, after which they were purified by gel filtration through Sephadex G-50 (5\%) (Sigma Aldrich), before they were analyzed on the 3730 DNA Analyzer (Applied Biosystems).

\subsection{Sequence alignment and phylogenetic analysis}

The DNA sequences were aligned by BioNumerics Seven software platform (Applied Maths) and compared with those from GenBank using BLASTn search. Sequences of FFSC strains were aligned with sequences of reference strains using the alignment with Clustal W algorithm (Thompson et al. 1994) in the MEGA 7.0 software (Tamura et al. 2013). Phylogenetic analyses were conducted with three housekeeping genes (TEF, CAL and TUB), individually and combined, and the DNA sequences of the strains obtained were compared with sequences from strains of reference species in the FFSC already available in GenBank (O'Donnell et al. 2009; Lima et al. 2009; Costa et al. 2019). Maximum Parsimony (MP) analyses were implemented in the MEGA 7.0 software and the clades stability were evaluated using 1000 parsimony bootstrap replicates. Fusarium oxysporum and Fusarium inflexum were used as outgroup. The generated sequences were deposited in the GenBank database under accession numbers LS423127 - LS423234 (TEF), LS423343 - LS423450 (CAL) and LS423235 - LS423342 (TUB) (Supplementary Table 1).

\subsection{In vitro culturing for mycotoxin analysis}

A subset of 61 strains representative of all phylogenetic species were selected for determining their ability to produce fumonisin B1 (FB1), fumonisin B2 (FB2) and fumonisin B3 (FB3), MON, BEA and ENNs, enniatins A (ENNA), enniatins A1 (ENNA1), enniatins B 
(ENNB) and enniatins B1 (ENNB1). For culturing, erlenmeyer flasks $(250 \mathrm{~mL})$ were filled with $30 \mathrm{~g}$ rice grains, $13 \mathrm{~mL}$ distilled water and autoclaved for $30 \mathrm{~min}$ at $121{ }^{\circ} \mathrm{C}$. After cooling each flask was inoculated with 5 plugs of $0.6 \mathrm{~cm}$ in diameter of each culture. Flask cultures were incubated in the dark 21 days at $25^{\circ} \mathrm{C}$. During the first 3 days flasks were shaken once daily to distribute the inoculum more evenly. After 21 days the culture were transferred into aluminum bags and were dried for 48 hours at $65{ }^{\circ} \mathrm{C}$ and then crushed. Controls were handled the same way, except that they were not inoculated. Details on the extraction and analysis of each mycotoxin were performed as follows.

\subsubsection{Determination of $F B_{1}, F B_{2}$ and $F B_{3}$}

One gram of rice culture was extracted with $5 \mathrm{~mL}$ of methanol/water $(75: 25, \mathrm{v} / \mathrm{v})$. Samples were placed for 60' in an orbital shaker, then were filtered using whatman no. 4 filters (Maidstone, UK). Five hundred microliters was diluted with $500 \mu \mathrm{L}$ ultrapure water (Millipore, Bedford, MA). $50 \mu \mathrm{L}$ of the extract was derivatized with $50 \mu \mathrm{L}$ of ophthaldialdehyde (OPA) mixed for 50 sec. using the HPLC autosampler Agilent 1100 (Agilent, Waldbronn, Germany) equipped with a binary pump, column thermostat set at $30^{\circ} \mathrm{C}, 100 \mu \mathrm{l}$ was injected by full loop at 3 min after adding the OPA reagent for fumonisins analysis. The analytical column was a Symmetry Shield RP18 $15 \mathrm{~cm}$ x 4,6 mm, $5 \mu \mathrm{m}$ (Waters) with a guard column inlet filter $(0.5 \mu \mathrm{m} \times 3 \mathrm{~mm}$ diameter, Rheodyne Inc. CA, USA) and the mobile phase consisted of a binary gradient was applied as follows: the initial composition of the mobile phase $57 \%$ of (A) water/ acetic acid (99:1, v/v) / 43\% of (B) acetonitrile/ acetic acid (99:1, v/v) was kept constant for 5 min, then B solvent was linearly increased to $54 \%$ in $21 \mathrm{~min}$, then up to $58 \%$ at $25 \mathrm{~min}$ and kept constant for $5 \mathrm{~min}$. The flow 
rate of the mobile phase was $0.8 \mathrm{~mL} / \mathrm{min}$. The fluorometric detector was set at wavelengths, ex $=335 \mathrm{~nm}$, em $=440 \mathrm{~nm}$. Retention time $\mathrm{FB}_{1}$ was about 16.6 minutes, $\mathrm{FB}_{2}$ was 24.6 min. and $\mathrm{FB}_{3}$ was $26.0 \mathrm{~min}$. FBs were quantified by measuring peak areas, and comparing them with a calibration curve obtained with standard solutions. Detection limit was $0.02 \mu \mathrm{g} / \mathrm{g}$ based on a signal-to-noise ratio of $3: 1$ for $\mathrm{FB}_{1}, \mathrm{FB}_{2}$ and $\mathrm{FB}_{3}$.

\subsubsection{Determination of MON}

One gram of rice culture was extracted with $5 \mathrm{~mL}$ of methanol/ water $(70: 30, \mathrm{v} / \mathrm{v})$ on an orbital shaker for 60 minutes. The residue was filtered using RC through $0.20 \mu \mathrm{m}$ regenerated cellulose filter (Phenomenex). $50 \mu \mathrm{L}$ of extract was injected into to HPLC apparatus (Agilent Technology Series 1260 series, Waldbronn, Germany) was equipped with a binary pump, an autosampler, a column thermostat set at $30^{\circ} \mathrm{C}$ and a DAD detector set at $228 \mathrm{~nm}$ and $260 \mathrm{~nm}$, respectively. The analytical column was a Symmetry C18 $150 \mathrm{x}$ 4,6 mm, $5 \mu \mathrm{m}$ (Waters, Milford, MA, USA) with a guard column inlet filter $(0.5 \mu \mathrm{m} \times 3 \mathrm{~mm}$ diameter, Rheodyne Inc. CA, USA). The mobile phase was a mixture of water/ formic acid (99:1, v/v, solvent A) and methanol/ formic acid (99:1, v/v, solvent B) eluted at a flow rate of $0.8 \mathrm{~mL} / \mathrm{min}$. A gradient elution was performed as following: $50 \%$ B solvent for $5 \mathrm{~min}$.; then was linearly increased to $70 \%$ in 2 min., $50 \%$ at 12 min. and kept constant for 5 min. The retention time of mycotoxin was about $2.7 \mathrm{~min}$. and the detection limits (LOD) were $0.13 \mu \mathrm{g} / \mathrm{g}$.

2.4.3. Determination of BEA and ENNA, ENNA1, ENNB and ENNB1 
One gram of rice culture was extracted with $5 \mathrm{~mL}$ of methanol/ water $(70: 30, \mathrm{v} / \mathrm{v})$ on an orbital shaker for 60 minutes, then was filtered using Whatman no. 4 filters (Waters, Milford, MA, USA). One hundred microliters was diluted with $900 \mu \mathrm{L}$ ultrapure water (Millipore, Bedford, MA) and filtered using RC through $0.20 \mu \mathrm{m}$ regenerated cellulose filter (Phenomenex, Torrance, CA, USA). $100 \mu \mathrm{L}$ of extract was injected into HPLC apparatus (Agilent 1260 Series, Agilent Technology, Santa Clara, CA, USA) was equipped with a binary solvent manager, a column heater set at $40^{\circ} \mathrm{C}$ and a diode array (DAD) detector that was set at $205 \mathrm{~nm}$ wavelength. The analytical column was a Gemini $(150 \times 4.6 \mathrm{~mm}, 5 \mu \mathrm{m}$, Phenomenex) preceded by a SecurityGuard ${ }^{\mathrm{TM}}$ cartridge Gemini (4 x $3 \mathrm{~mm}$, Phenomenex). The mobile phase was water as solvent $A$ and acetonitrile as solvent $\mathrm{B}$, eluted at a flow rate of $1 \mathrm{~mL} / \mathrm{min}$. A gradient elution was performed by changing the mobile phase composition as follows. After $5 \mathrm{~min}$ at $70 \%$ eluent B, the proportion was set at $90 \%$ in $10 \mathrm{~min}$, then kept constant for $3 \mathrm{~min}$. The column was re-equilibrated with $70 \%$ eluent B for $5 \mathrm{~min}$. In this analytical conditions, the retention time of BEA was about 11.4 min, ENNA 13 min, ENNA1 12 min, ENNB 9 min., ENNB1 10.3 min. and the detection limits (LOD) based on signal-tonoise ratio of 3:1, were the following: BEA $=0.01 \mu \mathrm{g} / \mathrm{g}$; ENNA $=0.2 \mu \mathrm{g} / \mathrm{g}$, ENNA1 $=0.5 \mu \mathrm{g} / \mathrm{g}$; $\mathrm{ENNB}=0.06 \mu \mathrm{g} / \mathrm{g}$ and $\mathrm{ENNB} 1=0.07 \mu \mathrm{g} / \mathrm{g}$.

\section{Results}

\subsection{Phylogenetic analysis}


The combined dataset (Figure 1) confirmed the monophyletics of species by the single-gene tree (Supplementary Figure 1). Individually, the TEF dataset provided 658 characters, of which 192 sites were polymorphic, and 141 of which were parsimony-informative. The housekeeping genes resulted in 4 most parsimonious trees with consistency index of 0.71 , retention index of 0.97 , and composite index of 0.76 for all sites. There were 272 parsimony informative sites among 1679 characters analyzed. The TEF tree was topologically concordant and the phylogeny inferred by the MP criterion allowed to identify eight phylogenetic species and one new phylogenetic species that we defined in this paper as Fusarium sp.. Three species accounted for around $60 \%$ of the strains and they were at similar frequency (16 to $23 \%): F$. fujikuroi $(\mathrm{n}=23), F$. proliferatum $(\mathrm{n}=22)$ and $F$. verticillioides $(n=16)$. The least frequent species was $F$. volatile $(n=8)$ that was grouped (100 \% support) with a NRRL 25615, isolated from rice seeds in Nigeria. Then, $F$. anthophilum $(\mathrm{n}=6)$, F. pseudocircinatum $(\mathrm{n}=4)$, F. sterilihyphosum $(\mathrm{n}=2)$ and F. begoniae $(n=1)$. Those species were identified with the statistical support bootstrap ranged from 87 to $100 \%$. Finally, the new phylogenetic species, Fusarium sp. $(\mathrm{n}=18)$ was identified with $100 \%$ bootstrap support and were placed in the African clade of the FFSC. These new species grouped (97\% support) together with strains from leaves and stems of sugarcane plants isolated from symptoms of pokkah boeng (CML 3561, CML 3578-3586) and very close to F. andiyazi (CBS 119857).

\subsection{Mycotoxin production}

All species produced at least one of the analyzed mycotoxins including fumonisins and beauvericin (Table 1) and enniatins and moniliformin (Table 2). 


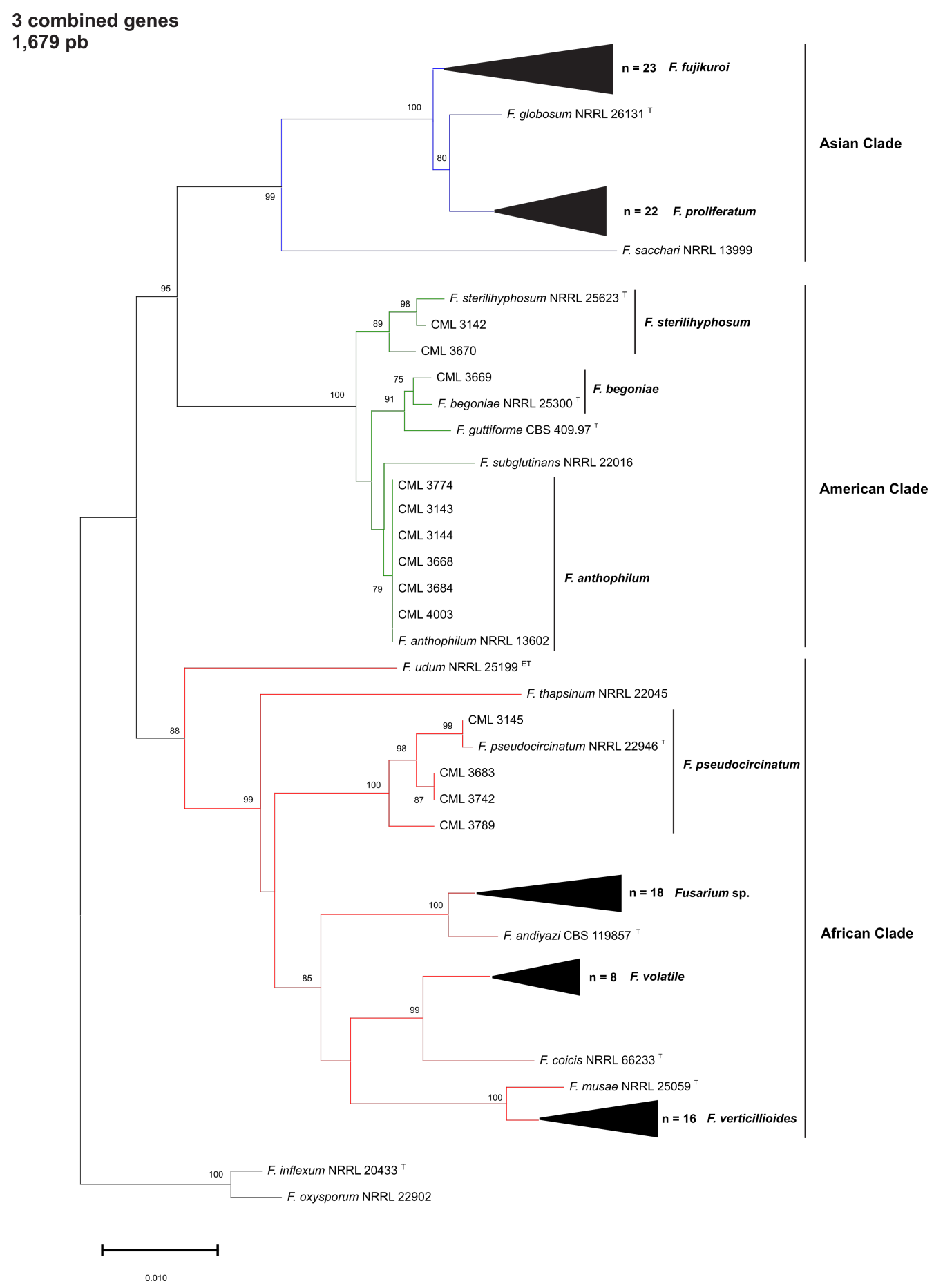

Figure 1. Phylogenetic tree inferred from the combined datasets $(T E F, T U B$ and $C A L)$ from members of the Fusarium fujikuroi species complex analyzed in this study. The evolutionary 
history was inferred by using the Maximum Parsimony method. Numbers on branches are bootstrap values based on 1000 replicates.

\subsubsection{Fumonisins}

The three fumonisin forms were produced by most isolates of $F$. fujikuroi, F. proliferatum and $F$. verticillioides. The isolates of $F$. anthophilum, F. sterilihyphosum and F. begonia did not produce fumonisins. All F. verticillioides, all F. proliferatum and all but one F. fujikuroi isolates produced $\mathrm{FB}_{1}$ in larger quantity than $\mathrm{FB}_{2}$ and $\mathrm{FB}_{3}$ (Table 1). One $F$. pseudocircinatum isolate produced only $\mathrm{FB}_{1}$ (Table 1 ). Two out of seven $F$. volatile isolates produced $\mathrm{FB}_{1}$ and five out of 18 Fusarium sp. Isolates produced $\mathrm{FB}_{1}$ and one isolate produced $\mathrm{FB}_{2}$ (Table 1 ).

\subsubsection{Beauvericin}

Beauvericin was produced by all species with the exception of $F$. verticillioides. In particular, all $F$. proliferatum isolates produced BEA. All but one $F$. fujikuroi isolate produced BEA. With respect to the less frequent species isolated, two strains of F. pseudocircinatum could produce BEA $(684.62-1,905.88 \mu \mathrm{g} / \mathrm{g})$, five out of six strains of $F$. anthophilum (67.891,810.63 $\mu \mathrm{g} / \mathrm{g}$ ), both strains of $F$. sterilihyphosum (38.66-44.51 $\mu \mathrm{g} / \mathrm{g}$ ) and also the single strain of $F$. begoniae produced BEA at a value of $54.33 \mu \mathrm{g} / \mathrm{g}$. Finally, he recently described specie and the new phylogenetic species strains produced BEA. In particular, all strains identified as F. volatile produced BEA $(68.05-3,466.87 \mu \mathrm{g} / \mathrm{g})$, while for Fusarium sp., four strains out of 18 strains identified produced BEA (6.66-17.29 $\mu \mathrm{g} / \mathrm{g})$. 
Table 1. Fumonisins and beauvericin produced by strains of Fusarium fujikuroi species complex grown on rice culture.

\begin{tabular}{|c|c|c|c|c|c|}
\hline \multirow[b]{2}{*}{ Species } & \multirow[b]{2}{*}{ No. } & \multicolumn{4}{|c|}{ Mycotoxins $(\mu \mathrm{g} / \mathrm{g})$} \\
\hline & & $\mathrm{FB}_{1}$ & $\mathrm{FB}_{2}$ & $\mathrm{FB}_{3}$ & BEA \\
\hline F. proliferatum & 8 & $8(1,348.7-4,637.9)$ & $8(401.2-3,650.1)$ & $8(39.8-3,491.5)$ & $8(244.1-857.8)$ \\
\hline F. volatile & 7 & $2(69.4-70.2)$ & - & - & $7(68.05-3,466.8)$ \\
\hline F. fujikuroi & 8 & $7(115.6-14,745)$ & $7(29.3-5,611.1)$ & $5(20.9-50.1)$ & $7(54.72-1,500.6)$ \\
\hline F. anthophilum & 6 & - & - & - & $5(67.89-1,810.6)$ \\
\hline Fusarium sp. & 18 & $5(98.6-195.10)$ & $1(6.3)$ & - & $4(6.66-17.29)$ \\
\hline F. pseudocircinatum & 4 & $1(70.5)$ & - & - & $2(684.6-1,905.8)$ \\
\hline F. sterilihyphosum & 2 & & & & $2(38.66-44.5)$ \\
\hline F. begoniae & 1 & & & & $1(54.3)$ \\
\hline F. verticillioides & 7 & $7(1,385.8-5,426.4)$ & $7(572.8-3,835.6)$ & $6(18.8-594.0)$ & - \\
\hline Total & 61 & 30 & 23 & 19 & 36 \\
\hline
\end{tabular}

\subsubsection{Enniatins}

The enniatins were produced by all species with the exception of $F$. begoniae and $F$. verticillioides. However, their production varied according with the single enniatin. ENNA was produced only by one out of eight tested strains of $F$. fujikuroi $(2.9 \mu \mathrm{g} / \mathrm{g})$; ENNA1 was produced by one strain each of F. pseudocircinatum $(26.8 \mu \mathrm{g} / \mathrm{g})$ and $F$. sterilihyphosum $(72.1$ $\mu \mathrm{g} / \mathrm{g}$ ), and 12 out strains of the 18 strains of the new phylogenetic species Fusarium sp. $(12.3-63.2 \mu \mathrm{g} / \mathrm{g})$; ENNB was produced only by one out of seven tested strains of the recently phylogenetic species $F$. volatile $(25.7 \mu \mathrm{g} / \mathrm{g})$. Finally, ENNB1 was produced by one out of the eight tested strains of F. proliferatum $(123 \mu \mathrm{g} / \mathrm{g})$, two strains out of the six tested strains of $F$. anthophilum (134-154 $\mu \mathrm{g} / \mathrm{g})$, one strain out of the seven tested of the recently 
phylogenetic specie $F$. volatile $(379 \mu \mathrm{g} / \mathrm{g})$ and nine out of 18 tested strains of the new phylogenetic Fusarium sp. (8-23 $\mu \mathrm{g} / \mathrm{g})$.

Table 2. Enniatins and moniliformin produced by strains of Fusarium fujikuroi species complex grown on rice culture.

\begin{tabular}{|c|c|c|c|c|c|c|}
\hline \multirow[b]{2}{*}{ Species } & \multirow[b]{2}{*}{ No. } & \multicolumn{5}{|c|}{ Mycotoxins $(\mu \mathrm{g} / \mathrm{g})$} \\
\hline & & ENNA & ENNA1 & ENNB & ENNB1 & MON \\
\hline F. fujikuroi & 8 & $1(2.9)$ & - & - & - & $8(301.73-2,982.8)$ \\
\hline F. proliferatum & 8 & - & - & - & $1(123)$ & $6(26.93-1,788.7)$ \\
\hline Fusarium sp. & 18 & - & $12(12.3-63.2)$ & - & $9(8.0-23.0)$ & $6(10.82-34.9)$ \\
\hline F. volatile & 7 & - & - & $1(25.7)$ & $1(379.0)$ & $3(77.72-464.8)$ \\
\hline F. verticillioides & 7 & - & - & - & - & $3(10.7-18.04)$ \\
\hline F. pseudocircinatum & 4 & - & $1(26.8)$ & - & - & $2(1,879.1-2,425.3)$ \\
\hline F. anthophilum & 6 & - & - & - & $2(134-154)$ & $1(30.96)$ \\
\hline F. begoniae & 1 & - & - & - & - & - \\
\hline F. sterilihyphosum & 2 & - & $1(72.1)$ & - & - & - \\
\hline Total & 61 & 1 & 14 & 1 & 13 & 29 \\
\hline
\end{tabular}

\subsubsection{Moniliformin}

All species but F. sterilihyphosum and F. begoniae produced MON. The top MON-producers were F. pseudocircinatum and F. fujikuroi. The production of MON was detected for: three $F$. verticillioides out of seven tested strains (range 10.7-18.04 $\mu \mathrm{g} / \mathrm{g}$ ); six F. proliferatum out of eight tested strains (range 26.93-1,788.7 $\mu \mathrm{g} / \mathrm{g}$ ); all F. fujikuroi strains (range 301.73$2,982.84 \mu \mathrm{g} / \mathrm{g}$ ). With respect to the less frequent species isolated, two strains of $F$. pseudocircinatum could produce MON $(1,879.08-2,425.3 \mu \mathrm{g} / \mathrm{g})$, and one out of six tested strains of $F$. anthophilum $(30.96 \mu \mathrm{g} / \mathrm{g})$. Finally, both the two new phylogenetic species 
strains produced MON. In particular, three strains out of seven tested strains of $F$. volatile produced MON (77.72-464.8 $\mu \mathrm{g} / \mathrm{g})$, while for Fusarium sp., six strains out of 18 tested strains produced MON (10.82-34.98 $\mu \mathrm{g} / \mathrm{g})$.

\section{Discussion}

This is the first comprehensive study that unravels the diversity and toxigenic potential of FFSC species strains from the most important tropical and subtropical rice-growing regions of Brazil. The number of FFSC species (nine clades) reported in our study is the greatest so far reported for fungi isolated from panicles or grains, to the best of our knowledge. Among them, F. fujikuroi, F. proliferatum and F. verticillioides were largely dominant, confirming previous reports worldwide (Carter et al. 2008; Wulff et al. 2010).

F. fujikuroi is known to dominate in rice kernels and not many other crops (Sunani et al. 2019). Confirming previous findings, those dominant species were capable of producing, depending on the isolate, relatively high amount of MON and BEA (Desjardins et al. 1997; Leslie and Summerell 2006), but F. fujikuroi was capable of producing all four classes. In particular, all isolates of this latter species produced high amounts of $\mathrm{FB}_{1}$, which does not agree with the literature (Desjardins et al. 1997). Fumonisin biosynthesis is dependent on the FUM cluster composed of 16 FUM genes (Proctor et al. 2013), but this has been found not only in fumonisin-producing strains, but also from fumonisin non-producing ones (Proctor et al. 2013). Recently, Sultana et al. (2019) revealed a natural genetic variation in the FUM gene cluster that is related to the fumonisin production difference in $F$. fujikuroi. The authors mapped causative mutations distributed in FUM7 and FUM21 genes of the fumonisin cluster by comparative analyses of FUM genes between the fumonisin producing 
and non-producing strains. Our F. fujikuroi isolates probably did not undergo such mutations and belong to a natural population of $F$. fujikuroi provided of full ability to produce fumonisins. Studies are in progress to confirm such hypothesis.

Different from F. fujikuroi, F. proliferatum is a common maize pathogen but also found in several plant hosts, including rice seeds and seedlings showing Bakanae symptoms as shown previously (Desjardins et al. 2000; Ma et al. 2010; Wulff et al. 2010; Nagaraja et al. 2016), including a recent report in Brazilian rice grain (Savi et al. 2018). Phylogenetically, F. proliferatum and F. fujikuroi are closely related toxigenic species (sibling species) (Leslie et al. 2004). The high amounts of BEA, MON and FBs produced by our $F$. proliferatum isolates confirms its high toxigenic potential (Desjardins 2006) and presence in rice, especially at regions where rice follows maize or soybean (Desjardins et al. 1997; Munkvold et al. 1997). Since $F$. verticillioides is the world's most known fumonisins-producing species (Desjardins 2006), its widespread occurrence on rice seeds in Brazil is worrisome for consumers, given their high potential to produce $\mathrm{FB}_{1}$ (Desjardins 2006) confirmed by our results.

Our report of $F$. anthophilum in Brazilian rice complements previous reports of its occurrence in bakanae affected plants in South African (Hossain et al. 2015) and in rice seeds of paddy or wild rice seeds in the northern USA (Nyvall et al. 1999) and in India (Nagaraja et al. 2016). In those, the species identity was determined based on morphology (Nyvall et al. 1999; Hossain et al. 2015) or sequences of the ITS region (Nagaraja et al. 2016). The ITS region is known to show insufficient nucleotide differences to distinguish among Fusarium spp., especially sibling species (Nilsson et al. 2008), a difficulty that is overcome when multi locus sequences are used for accurate identification, as in our study. This is critical for risk assessment, since $F$. anthophilum has been reported as a fumonisin C 
and BEA producing species, while $F$. subglutinans is not able to produce any of them (Moretti et al. 2007; Moretti et al. 2008; Proctor et al. 2013). We found that F. anthophilum isolates of our study produced BEA and MON, but not fumonisins, although it possesses biosynthetic genes to encode fumonisin biosynthesis (Proctor et al. 2004; Proctor et al. 2013).

The least frequent species F. begoniae, F. pseudocircinatum and F. sterilihyphosum are also first time reported in rice. Their biology and ecology are poorly understood. $F$. begoniae was first found infecting Begonia hybrids (Nirenberg and O'Donnell 1998) and F. pseudocircinatum and $F$. sterilihyphosum have been both reported as flowering-infecting pathogens of mango in Brazil (Lima et al. 2009), Mexico (Freeman et al. 2014) and Dominican Republic (García-López et al. 2016). F. sterilihyphosum was the only species found in mango in Egypt (Haggag et al. 2011).

The toxigenic potential of these species are also poorly known. F. begoniae has been reported as producer of high levels of MON, trace $\mathrm{FB}_{1}$ levels (Fotso et al. 2002) and no quantifiable levels of BEA (Fotso et al. 2002; Moretti et al. 2007). Contrastingly, our F. begonia isolates produced only BEA. The two F. sterilihyphosum isolates produced only BEA and ENNA1, which does not confirm its previous report of being a MON-producer (Haggag et al. 2011). Finally, F. pseudocircinatum produce FB 1 and MON (Footso et al. 2002) as well as BEA (Moretti et al. (2007). The production of ENNA1 by F. pseudocircinatum is the first. Since F. sterilihyphosum and F. pseudocircinatum are pathogens of mango, their toxigenic potential wars no the risk for this crop, which should be considered.

Species of the FFSC has been determined based on phylogenetic analyses that have also resolved the complex into three major lineages with different geographical origin: 
African, American and Asian clades (O'Donnell et al. 1998; Kvas et al. 2009). The F. volatile and new phylogenetic species (Fusarium sp.) fall into the African clade, together with $F$. verticillioides, that is closely related to both of them. Within this clase, F. volatile is more closely F. coicis and Fusarium sp. to F. andyazi. Fusarium coicis was isolated from Coix gasteenii, a plant growing in a natural ecosystem of minimal anthropogenic disturbance in Australia (Laurence et al. 2015). F. andiyazi was isolated from sorghum in Africa (Marasas et al. 2001). The high phylogenetic relatedness between two species occurring in such different environments is of particular interest due and provides insights into the geographic patterns of Fusarium evolution, challenging current phylogeographic hypotheses on FFSC members. Our set of eight isolates matched with Fusarium strains isolated from rice seeds (NRRL 25615) and a single isolate from a bronchoalveolar lavage sample of a female patient living in French Guiana used to describe a new species called $F$. volatile (Al-Hatmi et al. 2019). We report for the first time the potential of $F$. volatile to produce mycotoxins, a topic worthy of further investigation.

Finally, the new Fusarium sp. is a sister clade of $F$. andiyazi firstly isolated from sorghum from Africa (Marasas et al. 2001) but also from rice in Africa, Asia and California (Wulff et al. 2010), but not in our study. Our isolates are phylogenetically identical to isolates of a phylogenetic lineage recently isolated from sugarcane plants exhibiting symptoms of pokkah boeng in Brazil, where F. sacchari and F. proliferatum were also detected (Costa et al. 2019). The study showed that isolates of the new lineage were pathogenic to maize, sorghum and millet, causing a stem rot in all plants, evidencing a non host-specificity. Our Fusarium sp. isolates were capable of producing $\mathrm{FB}_{1}, \mathrm{MON}, \mathrm{BEA}$, and ENNs, which increases its importance of contaminant of rice. The knowledge of this 
increased diversity of Fusarium in rice is essential for risk assessment and management strategies for risk mitigation.

In conclusion, our study increases considerably knowledge of the diversity of Fusarium species infecting rice. Current legislation for tolerated maximum limits of Fusarium mycotoxins in Brazilian rice grains considers only ZEA and DON (ANVISA 2017). The importance of rice as a major staple food for domestic consumption and the presence of several mycotoxin-producing FFSC species reinforce the need to expand the analysis of mycotoxins in rice beyond those considered by the current legislation.

\section{Acknowledgements}

Authors are thankful to the Programa de Pós-graduação em Agronomia/ Fitopatologia (UFLA), Conselho Nacional de Desenvolvimento Científico e Tecnológico (CNPq) for providing a graduate scholarship (Proc. 200797/2017-4) and grateful to for a research fellowship (Proc. 457304/2014-6) and to the Institute of Sciences of Food Production (ISPA-CNR) for a great collaboration with our work.

\section{References}

Al-Hatmi, A.M.S., Sandoval-Denis, M., Nabet, C., Ahmed, S.A., Demar, M., Normand, A.C. and de Hoog, G.S., 2019. Fusarium volatile, a new potential pathogen from a human respiratory sample. Fungal Systematics and Evolution, 4, 171-181.

Amaral, M., Regina, E.D.E., Ferreira, A.C., Fazio, G.M., 1970. Studies on "Bakanae" disease of Rice in Sao Paulo State. Journal Biologico 36, 235-240.

Amatulli, M.T., Spadaro, D., Gullinoa, M.L., Garibaldi, A., 2010. Molecular identification of Fusarium spp. associated with bakanae disease of rice in Italy and assessment of their pathogenicity. Plant Pathol. 59, 839-844. 
AMIS - Agricultural Market Information System, 2019. Retrieved from: <http://www.amisoutlook.org/fileadmin/user_upload/amis/docs/Market_monitor/AMIS_Market_Monitor_current.pd $\mathrm{f}>$.

ANVISA - Agência Nacional de Vigilância Sanitária, 2017. Retrieved from <http://portal.anvisa.gov.br/documents/10181/3219534/RDC_138_2017_.pdf/b36e60b0-511243dc-9142-932f502fc46b?version>.

Avila, C.F., Moreira, G.M., Nicolli, C.P., Gomes, L.B., Abreu, L.M., Pfenning, L.H., Haidukowski, M., Moretti, A., Logrieco, A., Del Ponte, E.M., 2019. Fusarium incarnatum-equiseti species complex associated with Brazilian rice: Phylogeny, morphology and toxigenic potential. Int. J Food Microbiol. $306,108267$.

Bacon, C.W., Porter, J.K., Norred, W.P., Leslie, J.F., 1996. Production of fusaric acid by Fusarium species. Appl. Environ. Microbiol. 62, 4039-4043.

Bansal, J., Pantazopoulos, P., Tam, J., Cavlovic, P., Kwong, K., Turcotte, A.M., Lau, B.Y. and Scott, P.M., 2011. Surveys of rice sold in Canada for aflatoxins, ochratoxin A and fumonisins. Food Add Contam A. 28, 767-774.

Bashyal, B.M., 2018. Etiology of an emerging disease: bakanae of rice. Indian Phytopathol. 71, 485494.

Carter, L.L.A., Leslie, J.F., Webster, R.K., 2008. Population Structure of Fusarium fujikuroi from California Rice and Water Grass. Phytopathology. 98, 992-998.

Costa, M.M., Melo, M.P., Guimarães, E.A., Veiga, C.M.O., Carmo, Sandin F., Moreira, G.M., Costa, S.S., Pfenning, L.H., 2019. Identification and pathogenicity of Fusarium species associated with pokkah boeng of sugarcane in Brazil. Plant Pathol. 68, 1350-1360.

Desjardins, A.E., Plattner, R.D. and Nelson, P.E., 1997. Production of Fumonisin B (inf1) and Moniliformin by Gibberella fujikuroi from Rice from Various Geographic Areas. Appl. Environ. Microbiol. 63, 1838-1842.

Desjardins, A.E., Manandhar, H.K., Plattner, R.D., Manandhar, G.G., Poling, S.M., Maragos, C.M., 2000. Fusarium species from Nepalese rice and production of mycotoxins and gibberellic acid by selected species. Appl. Environ. Microbiol. 66, 1020-1025.

Desjardins, A.E., 2006. Fusarium mycotoxins: chemistry, genetics, and biology. American Phytopathological Society (APS Press).

ERS - Economic Research Service, 2019. Retrieved from: <https://www.ers.usda.gov/webdocs/publications/93502/rcs-19g.pdf?v=9137.6>. 
Fotso, J., Leslie, J.F. and Smith, J.S., 2002. Production of beauvericin, moniliformin, fusaproliferin, and fumonisins B1, B2, and B3 by fifteen ex-type strains of Fusarium species. Appl. Environ. Microbiol. 68, 5195-5197.

Freeman, S., Otero-Colina, G., Rodríguez-Alvarado, G., Fernández-Pavía, S., Maymon, M., Ploetz, R.C., Aoki, T., O’Donnell K., 2014. First Report of Mango Malformation Disease Caused by Fusarium pseudocircinatum in Mexico. Disease Notes. 98, 1583.

García-López, E.L.V.I.S., Mora-Aguilera, J.A., Nava-Diaz, C., Villegas-Monter, A.N.G.E.L., Tovar-Pedraza, J.M., Serra, C., Batista-Marte, C.M., 2016. First report of Fusarium pseudocircinatum causing mango malformation disease in Dominican Republic. Plant Dis. 100, 1501-1501.

Glass, N.L., Donaldson, G.C., 1995. Development of primer sets designed for use with the PCR to amplify conserved genes from filamentous ascomycetes. Appl. Environ. Microbiol. 61, 1323-1330.

Gomes, L.B., Ward, T.J., Badiale-Furlong, E., Del Ponte, E.M., 2015. Species composition, toxigenic potential and pathogenicity of Fusarium graminearum species complex isolates from southern Brazilian rice. Plant Pathol. 69, 980-987.

Gonçalves, A., Gkrillas, A., Dorne, J.L., Dall'Asta, C., Palumbo, R., Lima, N., Battilani, P., Venâncio, A., Giorni, P., 2019. Pre-and Postharvest Strategies to Minimize Mycotoxin Contamination in the Rice Food Chain. Compr. Rev. Food Sci. Food Saf. 18, 441-454.

Haggag, M.W., Hazza, M., Sehab, A., El-Wahab, M.A., 2011. Mango malformation: I. Toxin production associated with fusarium pathogens. Am. J. Plant Sci. 2, 276-281.

Hossain, M.T., Modise, D.M. and Rong, I.H., Anis Mahomed Karodia, 2015. "Pathogenicity of Fusarium Anthophilum and Fusarium Fujikuroi associated with Bakanae disease of rice: a fandmark study undertaken in South Africa". International Journal of Current Research, 7, 171.

Islam, N.F. and Borthakur, S.K., 2012. Screening of mycota associated with Aijung rice seed and their effects on seed germination and seedling vigour. Pl. Pathol. Quarant. 2, 75-85.

Kanaan, Y.M. and Bahkali, A.H., 1993. Frequency and cellulolytic activity of seed-borne Fusarium species isolated from Saudi Arabian cereal cultivars/Häufigkeit und zellulolytische Aktivität samenbürtiger Fusarium-Arten an Getreidesorten in Saudiarabien. J Plant. Dis. Protect. 100, 291298.

Kim, Y., Kang, I.J., Shin, D.B., Roh, J.H., Heu, S., Shim, H.K., 2018. Timing of Fusarium Head Blight Infection in Rice by Heading Stage. Mycobiology. 46, 283-286. 
Kvas, M., Marasas, W.F.O., Wingfield, B.D., Wingfield, M.J. and Steenkamp, E.T. 2009. Diversity and evolution of Fusarium species in the Gibberella fujikuroi complex. Fungal Divers. 34, 1-21.

Laurence, M.H., Walsh, J.L., Shuttleworth, L.A., Robinson, D.M., Johansen, R.M., Petrovic, T., Vu, T.T.H., Burgess, L.W., Summerell, B.A., Liew, E.C.Y., 2015. Six novel species of Fusarium from natural ecosystems in Australia. Fungal Divers. 77, 349-366.

Lee, S., Son, H., Lee, J., Lee, Y.R., Lee, Y.W., 2011. A putative ABC transporter gene, ZRA1, is required for zearalenone production in Gibberella zeae. Current genetics. 57, 343.

Leslie, J.F., Zeller, K.A., Logrieco, A., Mule, G., Moretti, A. and Ritieni, A., 2004. Species diversity of and toxin production by Gibberella fujikuroi species complex strains isolated from native prairie grasses in Kansas. Appl. Environ. Microbiol. 70, 2254-2262.

Leslie J.F., Summerell B.A., 2006. The Fusarium Laboratory Manual. Blackwell Professional, Ames, Iowa.

Lima, C.S., Pfenning, L.H., Costa, S.S., Campos, M.A., Leslie, J.F., 2009. A new Fusarium lineage within the Gibberella fujikuroi species complex is the main causal agent of mango malformation disease in Brazil. Plant Pathol. 58, 33-42.

Logrieco, A., Moretti, A., Castella, G., Kostecki, M., Golinski, P., Ritieni, A., Chelkowski, J., 1998. Beauvericin Production by Fusarium Species. Appl. Environ. Microbiol. 64, 3084-3088.

Ma, L.J., Van Der Does, H.C., Borkovich, K.A., Coleman, J.J., Daboussi, M.J., Di Pietro, A., Dufresne, M., Freitag, M., Grabherr, M., Henrissat, B. and Houterman, P.M., 2010. Comparative genomics reveals mobile pathogenicity chromosomes in Fusarium. Nature, 464, 367.

Majeed, S., De Boevre, M., De Saeger, S., Rauf, W., Tawab, A., Rahman, M., Iqbal, M., 2018. Multiple mycotoxins in rice: Occurrence and health risk assessment in children and adults of Punjab, Pakistan. Toxins. 10, 77.

Marasas, W. F. O., 1986. "Fusarium moniliforme: A mycotoxicological miasma". In Mycotoxins and Phycotoxins, Edited by: Steyn, P. S. and Vleggaar, R. 19-28. Amsterdam: Elsevier Science.

Marasas, W.F., Rheeder, J.P., Lamprecht, S.C., Zeller, K.A., Leslie, J.F., 2001. Fusarium andiyazi sp. nov., a new species from sorghum. Mycologia. 93, 1203-1210.

Marasas, W.F., Riley, R.T., Hendricks, K.A., Stevens, V.L., Sadler, T.W., Gelineau-van Waes, J., Missmer, S.A., Cabrera, J., Torres, O., Gelderblom, W.C. and Allegood, J., 2004. Fumonisins disrupt sphingolipid metabolism, folate transport, and neural tube development in embryo culture and in vivo: a potential risk factor for human neural tube defects among populations consuming fumonisincontaminated maize. Br. J. Nutr. 134, 711-716. 
Moretti, A. 1996. Diversity in beauvericin and fusaproliferin production by different populations of Gibberella fujikuroi (Fusarium section Liseola). Sydowia. 48, 44-56.

Moretti, A., Mule, G., Ritieni, A. and Logrieco, A., 2007. Further data on the production of beauvericin, enniatins and fusaproliferin and toxicity to Artemia salina by Fusarium species of Gibberella fujikuroi species complex. Int. J. Food Microbiol. 118, 158-163.

Moretti, A., Mulé, G., Ritieni, A., Láday, M., Stubnya, V., Hornok, L. and Logrieco, A., 2008. Cryptic subspecies and beauvericin production by Fusarium subglutinans from Europe. Int. J. Food Microbiol. 127, 312-315.

Munkvold, G.P., Hellmich, R.L. and Showers, W.B., 1997. Reduced Fusarium ear rot and symptomless infection in kernels of maize genetically engineered for European corn borer resistance. Phytopathology. 87, 1071-1077.

Nagaraja, H., Chennappa, G., Rao, K.P.C., Prasad, G.M. and Sreenivasa, M.Y., 2016. Diversity of toxic and phytopathogenic Fusarium species occurring on cereals grown in Karnataka state, India. 3 Biotech. 6, 57.

Neme, K., Mohammed, A., 2017. Mycotoxin occurrence in grains and the role of postharvest management as a mitigation strategies. A review. Food Control. 78, 412-425.

Nicholson, P., Simpson, D.R., Wilson, A.H., Chandler, E. and Thomsett, M., 2004. Detection and differentiation of trichothecene and enniatin-producing Fusarium species on small-grain cereals. In Molecular Diversity and PCR-detection of Toxigenic Fusarium Species and Ochratoxigenic Fungi (pp. 503-514). Springer, Dordrecht.

Nirenberg, H.I. and O'Donnell, K., 1998. New Fusarium species and combinations within the Gibberella fujikuroi species complex. Mycologia. 90, 434-458.

Nilsson, R.H., Kristiansson, E., Ryberg, M., Hallenberg, N. and Larsson, K.H., 2008. Intraspecific ITS variability in the kingdom Fungi as expressed in the international sequence databases and its implications for molecular species identification. Evol bioinform. 4, EBO-S653.

Nyvall, R.F., Percich, J.A., Mirocha, C.J., 1999. Fusarium head blight of cultivated and natural wild rice (Zizania palustris) in Minnesota caused by Fusarium graminearum and associated Fusarium spp. Plant Dis. 83, 159-164.

O'Donnell, K., Cigelnik, E., Nirenberg, H.I., 1998. Molecular systematics and phylogeography of the Gibberella fujikuroi species complex. Mycologia. 90, 465-493. 
O'Donnell, K., Corby Kistler, H., Tacke, B.K., Casper, H.H., 2000. Gene genealogies reveal global phylogeographic structure and reproductive isolation among lineages of Fusarium graminearum, the fungus causing wheat scab. PNAS 97, 7905-7910.

O’Donnell, K., Gueidan, C., Sink, S., Johnston, P.R., Crous, P.W., Glenn, A., Riley, R., Zitomer N.C., Colyer P., Waalwijk C., van der Lee, T., 2009. A two-locus DNA sequence database for typing plant and human pathogens within the Fusarium oxysporum species complex. Fungal Genet. Biol. 46, 936-948.

O’Donnell, K., Ward, T.J., Robert, V.A., Crous, P.W., Geiser, D.M. and Kang, S., 2015. DNA sequencebased identification of Fusarium: current status and future directions. Phytoparasitica. 43, 583-595.

Plattner, R.D., Maragos, C.M., 2003. Determination of deoxynivalenol and nivalenol in corn and wheat by liquid chromatography with electrospray mass spectrometry. J. AOAC Int. 86, 61-65.

Proctor, R.H., Plattner, R.D., Brown, D.W., Jeong-Ah, S.E.O., Yin-Won, L.E.E., 2004. Discontinuous distribution of fumonisin biosynthetic genes in the Gibberella fujikuroi species complex. Mycological Res. 108, 815-822.

Proctor, R.H., Van Hove, F., Susca, A., Stea, G., Busman, M., van der Lee, T., Waalwijk, C., Moretti, A., Ward, T.J., 2013. Birth, death and horizontal transfer of the fumonisin biosynthetic gene cluster during the evolutionary diversification of Fusarium. Mol. Microbiol. 90, 290-306.

Rheeder, J.P., Marasas, W.F., Vismer, H.F., 2002. Production of fumonisin analogs by Fusarium species. Appl. Environ. Microbiol. 68, 2101-2105.

Savard, M.E., Miller, J.D., Salleh, B. and Strange, R.N., 1990. Chlamydosporol, a new metabolite from Fusarium chlamydosporum. Mycopathologia. 110, 177-181.

Savi, G.D., Piacentini, K.C., Rocha, L.O., Carnielli-Queiroz, L., Furtado, B.G., Scussel, R., Zanoni, E.T., Machado-de-Ávila, R.A., Corrêa, B., Angioletto, E., 2018. Incidence of toxigenic fungi and zearalenone in rice grains from Brazil. Int. J. Food Microbiol. 270, 5-13.

Shi, W., Tan, Y., Wang, S., Gardiner, D., De Saeger, S., Liao, Y., Wang, C., Fan, Y., Wang, Z. and Wu, A., 2017. Mycotoxigenic potentials of Fusarium species in various culture matrices revealed by mycotoxin profiling. Toxins. 9, 6.

Sobrova, P., Adam, V., Vasatkova, A., Beklova, M., Zeman, L., Kizek, R., 2010. Deoxynivalenol and its toxicity. Interdiscip. Toxicol. 3, 94-99.

Soleimany, F., Jinap, S., Faridah, A., Khatib, A., 2012. A UPLC-MS/MS for simultaneous determination of aflatoxins, ochratoxin A, zearalenone, DON, fumonisins, T-2 toxin and HT-2 toxin, in cereals. Food Control. 25, 647-653. 
Sunani, S.K., Bashyal, B.M., Kharayat, B.S., Prakash, G., Krishnan, S.G. and Aggarwal, R., 2019. Identification of rice seed infection routes of Fusarium fujikuroi inciting bakanae disease of rice. Journal of Plant Pathology, 1-9.

Sultana, S., Kitajima, M., Kobayashi, H., Nakagawa, H., Shimizu, M., Kageyama, K. and Suga, H., 2019. A Natural Variation of Fumonisin Gene Cluster Associated with Fumonisin Production Difference in Fusarium fujikuroi. Toxins. 11, 200.

Tamura, K., Stecher, G., Peterson, D., Filipski, A., Kumar, S., 2013. MEGA 6: molecular evolutionary genetics analysis, version 6.0. Mol. Biol. Evol. 30, 2725-2729.

Tanaka, K., Sago, Y., Zheng, Y., Nakagawa, H., Kushiro, M., 2007. Mycotoxins in rice. Int. J. Food Microbiol. 119, 59-66.

Thompson, J.D., Higgins, D.G., Gibson, T.J., 1994. CLUSTAL W: improving the sensitivity of progressive multiple sequence alignment through sequence weighting, position-specific gap penalties and weight matrix choice. Nucleic Acids Res. 22, 4673-4680.

Wulff, E.G., Sorensen, J.L., Lübeck, K.F.N., Thrane, U., Torp, J., 2010. Fusarium spp. associated with rice bakanae: ecology, genetic diversity, pathogenicity and toxigenicity. Environ. Microbiol. 12, 649657.

Zainudin, N.A.I.Z., Razak, A.A., Salleh, B., 2008. Bakanae disease of rice in Malaysia and Indonesia: etiology of the causal agent based on morphological, physiological and pathogenicity characteristics. J. Plant Prot. Res. 48, 475-485. 


\section{Supplemental material}

TEF

$658 \mathrm{pb}$

1 of 3 trees

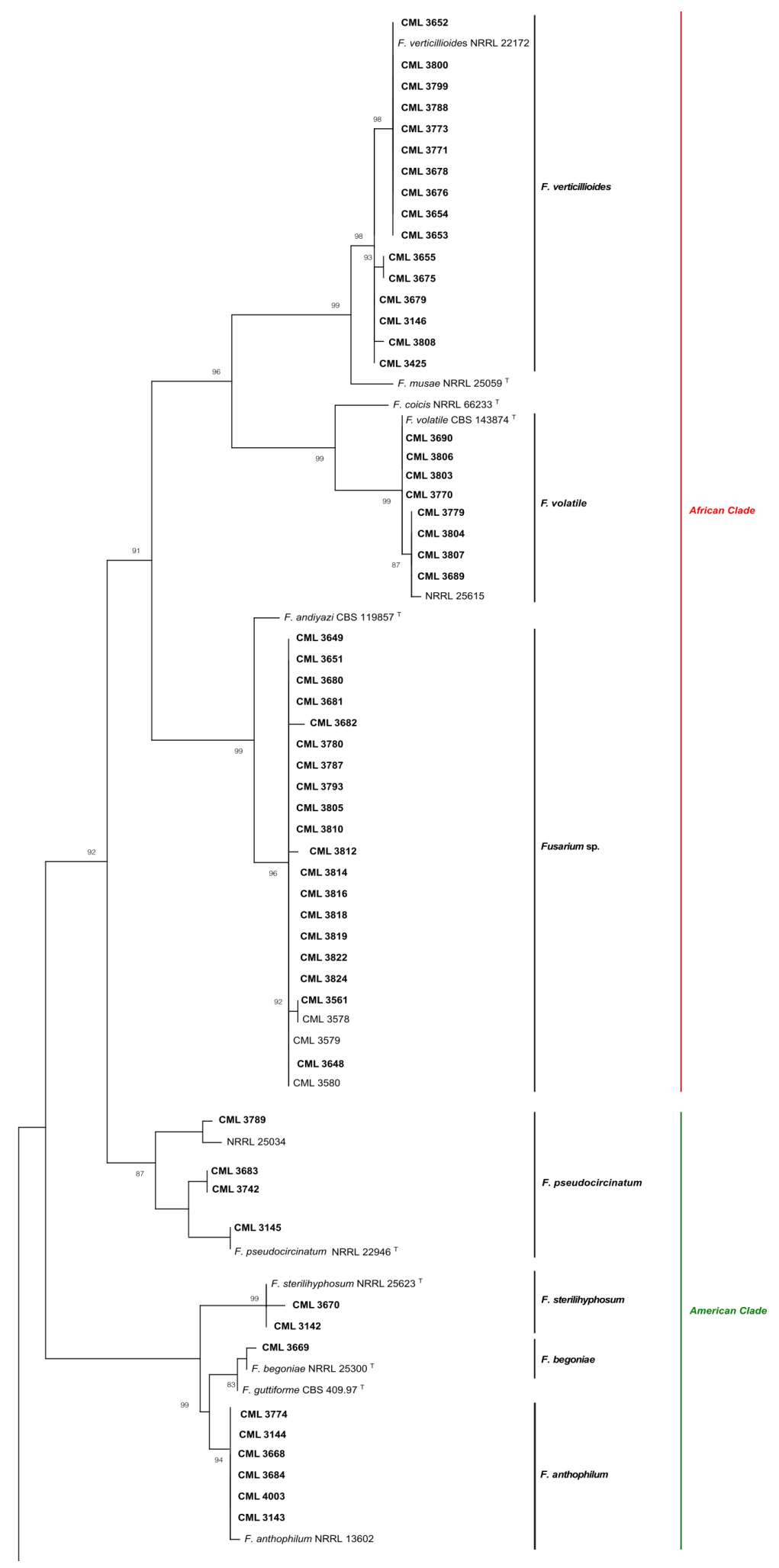




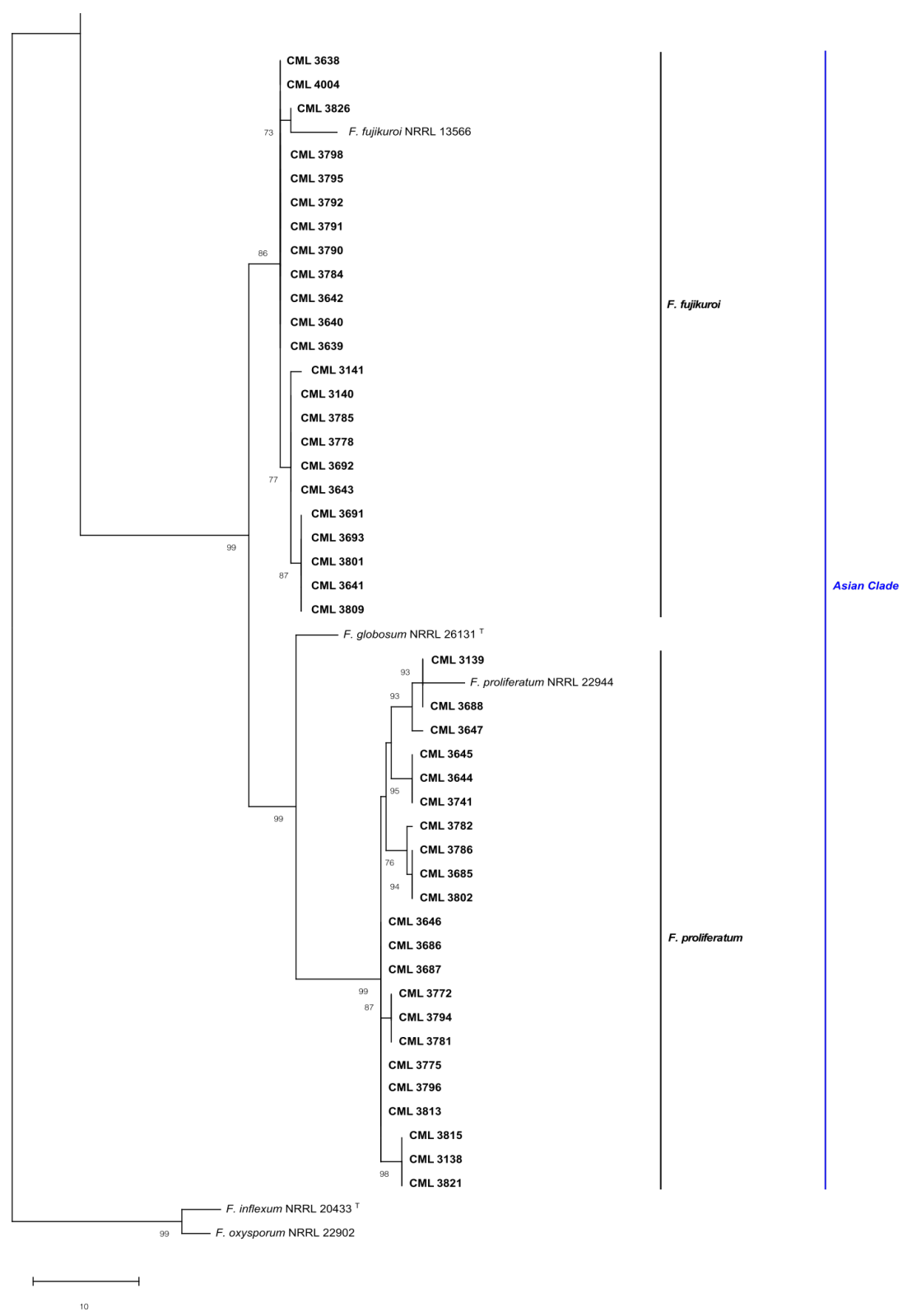

Supplementary Figure 1. Phylogenetic tree inferred by partial TEF gene sequences from members of the Fusarium fujikuroi species complex analyzed in this study. The evolutionary history was inferred by using the Maximum Parsimony method. Numbers on branches are bootstrap values based on 1000 replicates 
Supplementary Table 1. Strains of Fusarium fujikuroi species complex isolated from rice in Brazil identified by molecular phylogeny and the mycotoxins produced by strains grown on rice grains 